\title{
CÉLIO IN THE SKY WITH DIAMONDS: HIV/AIDS E MORTE EM UM POEMA DE ANGÉLICA FREITAS ${ }^{1}$
}

\author{
CÉLIO IN THE SKY WITH DIAMONDS: HIVIAIDS AND DEATH IN A POEM BY \\ ANGÉLICA FREITAS
}

Recebido: 09/02/2021

Aprovado: 21/06/2021

Publicado: $30 / 07 / 2021$

DOI: $10.18817 /$ rlj.v5i01.2519

\author{
Leandro Noronha da Fonseca ${ }^{2}$ \\ Orcid ID: https://orcid.org/0000-0002-8863-5013
}

\begin{abstract}
Resumo: Para além de seus contornos biomédicos, a questão do HIV/aids marca presença em diversas linguagens artísticas, inclusive na literatura, principalmente nas mais distintas vertentes da prosa. O presente trabalho parte da importância de Tente entender o que tento dizer (Bazar do Tempo, 2018), antologia poética voltada ao HIV/aids, e também da potencialidade de investigação sobre a temática na poesia contemporânea brasileira. Tendo como objeto de análise um dos poemas da antologia, "Célio no céu, com toda a sorte de pedras preciosas", escrito por Angélica Freitas, é possível observar que o tema do HIV/aids é elaborado a partir de uma tonalidade melancólica, mas profundamente leve diante de questões "tabu" como a morte e o sexo. Tendo em vista o histórico processo de estigmatização relacionado ao HIV/aids, o poema humaniza a questão e possibilita ao leitor reflexões sobre sexualidade de maneira mais aberta.
\end{abstract}

Palavras-chave: HIV/aids. Angélica Freitas. Poesia contemporânea brasileira.

Abstract: Apart from its biomedical topics, the issue of HIV/AIDS presents in several artistic languages, including literature, and mainly in the most distinct aspects of prose. The present paper is based on the importance together with the potential for investigating HIV/AIDS in contemporary Brazilian poetry, and it is using the poetic anthology Tente entender o que tento dizer published by Bazar do Tempo company in 2018. The object of this analysis is "Célio no céu, com toda a sorte de pedras preciosas", one of the poems from the anthology, written by Angélica Freitas. And there, it is possible to observe that the theme of HIV/AIDS is elaborated from a melancholic tone, but lightly in the face of "taboo" issues such as death and sex. When we consider the historical process of stigmatization related to HIV/AIDS, the poem humanizes that issue and allows the reader to reflect on the sexuality issue more openly.

Keywords: HIV/AIDS. Angélica Freitas. Brazilian contemporary poetry.

\section{Considerações iniciais sobre literatura brasileira e HIV/aids}

Desde o seu surgimento no início da década de 1980 até a atualidade, o HIV/aids é um fenômeno que marcou globalmente as sociedades. Para além de suas dimensões biomédicas, a questão marca presença também nas mais diversas expressões artísticas, incluindo a literatura.

\footnotetext{
${ }^{1}$ O presente trabalho foi realizado com apoio da Coordenação de Aperfeiçoamento de Pessoal de Nível Superior - Brasil (CAPES) - Código de Financiamento 001, e também da Universidade Federal de Mato Grosso do Sul - UFMS/MEC - Brasil.

${ }^{2}$ Mestrando em Letras pela Universidade Federal do Mato Grosso do Sul, Campus Três Lagoas (UFMS/CPTL) e bolsista CAPES. E-mail: Ifonseca954@gmail.com.
} 
Altman (1995) pontua que diversas respostas culturais surgiram no período de maior latência da epidemia. Elas visavam preservar a memória das vidas perdidas em decorrência da aids, lançando um olhar mais humanizado sobre a questão, tendo em vista o preconceito e a discriminação em torno do HIV/aids. Desde a música até o cinema, o tema foi abordado principalmente pelas pessoas mais atingidas pela epidemia: "[...] certamente, muito da literatura e das performances vem de pessoas que são soropositivas, e, portanto, elas escrevem, dançam e cantam suas próprias vidas" (ALTMAN, 1995, p. 121, grifo do autor).

Trazendo a questão para a realidade brasileira, Bessa (1997) observa que a temática está presente em diversas obras do escritor gaúcho Caio Fernando Abreu (1948-1996) e do escritor, ensaísta e ativista político Herbert Daniel (1946-1992). Para além da literatura de ficção, Bessa (2002) pontua que obras autobiográficas também abordaram a questão, principalmente por escritores soropositivos, como é o caso de Alberto Guzik, Jean-Claude Bernardet, Valéria Piassa Polizzi, entre outros.

Existe uma predominância nas pesquisas sobre literatura e HIV/aids no Brasil voltadas à prosa ficcional, em específico sobre os contos, romances e crônicas de Caio Fernando Abreu. Autores como Bessa (1997; 2002), Mendes (1998), Oliveira (2010), Batista (2016) e Alós (2017) já trouxeram reflexões neste sentido. Assim, nos parece proveitoso explorar outra seara literária: a poesia.

Conforme Fonseca (2019), o tema ganha espaço privilegiado na poesia contemporânea brasileira na obra Tente entender o que tento dizer, organizada pelo poeta e jornalista carioca Ramon Nunes Mello e publicada em 2018 pela editora Bazar do Tempo. É a primeira antologia poética publicada no Brasil voltada especificamente ao tema do HIV/aids. A obra reúne 101 poemas de 96 poemas brasileiros, de diversas regiões e trajetórias literárias. Entre os autores que integram a coletânea estão Silviano Santiago, Elisa Lucinda, Antonio Carlos Secchin, André Vallias, Chacal, Luís Capucho, Antonio Cicero, Annita Costa Malufe, Fabrício Corsaletti, entre outros.

Diante da amplidão de obras inseridas na coletânea, e da delimitação necessária para qualquer trabalho investigativo, trazemos para o centro da análise 0 poema "Célio no céu, com toda a sorte de pedras preciosas". O poema foi escrito pela poeta gaúcha Angélica Freitas, que publicou em 2007 o livro Rilke shake pela editora Cosac Naify. Pela mesma editora foi publicado, em 2012, o livro Um útero é do tamanho de um punho, obra que ganhou, no mesmo ano, o prêmio de melhor 
livro de poesia da Associação Paulista de Críticos de Arte (APCA). Em 2017, a obra foi reeditada pela editora Companhia das Letras pelo selo "Poesia de bolso". Mais recentemente, em 2020, lançou a obra Canções de atormentar, também pela Companhia das Letras.

As pesquisas em torno de Angélica Freitas, como podemos observar em Pietrani (2013), Frighetto (2015) e Miguel (2017), se debruçam sobre as temáticas predominantes em seus trabalhos poéticos, como a crítica ao machismo e a condição da mulher diante do patriarcado, entre outras problemáticas, e também sobre sua identidade estilística, voltada ao humor e à ironia como ferramentas de crítica social. A intersecção entre o HIV/aids e a poesia de Angélica Freitas ainda não foi explorada - temática, inclusive, praticamente ausente em seu conjunto de obras -, o que justifica a escolha de seu poema "Célio no céu, com toda a sorte de pedras preciosas" como objeto de análise do presente trabalho.

\section{O céu e as aventuras de Célio: analisando Angélica Freitas}

Antes de nos voltarmos para o poema em específico, se faz necessário um olhar mais amplo sobre o local onde o texto está inserido na coletânea temática. Como colocado acima, a antologia Tente entender o que tento dizer (Bazar do Tempo, 2018) traz a questão do HIV/aids como eixo central. Ramon Nunes Mello organizou a obra a partir de três partes temáticas: "[...] a linguagem; os poemas dedicados às vítimas da epidemia; e um eixo mais complexo que comporta o corpo, a vida, o cotidiano, ou o tempo e seus desdobramentos" (MELLO, 2018, p. 20). O poema de Angélica Freitas está inserido na Parte II da antologia, ou seja, voltada à memória das pessoas que morreram em decorrência da aids. Todavia, a pauta do HIV/aids não se dá de maneira explícita, obrigando um olhar mais atento do leitor sobre a estrutura do texto da poeta gaúcha.

$\begin{array}{ll}1 & \text { você levou } \\ 2 & \text { um policial militar } \\ 3 & \text { para a tua casa, } \\ 4 & \text { e a farda, } \\ 5 & \text { jogada de qualquer jeito } \\ 6 & \text { sobre o abajur, } \\ 7 & \text { queimou em círculos. } \\ 8 & \text { por que me lembro disso } \\ 9 & \text { quase trinta anos depois? } \\ 10 & \text { porque é engraçado. }\end{array}$


11 a gente ria o tempo todo.

12 e aquela história

13 de passar no banheiro

14 da praça -

15 um dia eu fui e vi, afinal,

16 a tua cara de felicidade

17 ao entrar no recinto -

18 muito alerta -

19 você era uma antena -

20 um olho na interlocutora,

21 outro no transeunte.

22 era uma cidade

23 com tão poucas possibilidades

24 que toda essa atividade

25 me parecia fascinante.

26 aventuras

27 numa época

28 em que o município

29 significava

30 o fim do mundo:

31 só as tuas.

32 você ficou,

33 eu fui embora.

34 de você, não soube mais nada,

35 até que me contaram.

36 quando volto

37 e passo na frente da tua casa,

38 um apartamento térreo,

39 de esquina,

40 perto do centro,

41 me pergunto se naquela época

42 você já sabia,

43 mas a pergunta é ociosa.

44 e me lembro

45 do brilho nos teus olhos.

(FREITAS, 2018, p. 100-101)

O título "Célio no céu, com toda a sorte de pedras preciosas" nos remete a algumas interpretações. A primeira delas é o nome "Célio", que, do latim, significa "celeste, celestial" (GUÉRIOS, 1981, p. 90). O nome faz referência ao "no céu" do título: o céu não apenas como destino de Célio no final da vida, mas lugar de sua própria origem. O "no céu" também indica que Célio não faz mais parte do mundo dos vivos.

A expressão "Célio no céu" remete ao poema "Irene no céu", de Manuel Bandeira. No texto de Bandeira (1986), o sujeito lírico apresenta Irene, mulher negra, "boa e sempre de bom humor", e a imagina entrar no céu, sendo recebida com gentileza por São Pedro. 
Irene sempre de bom humor.

Imagino Irene entrando no céu:

- Licença, meu branco!

E São Pedro bonachão:

- Entra, Irene. Você não precisa pedir licença.

(BANDEIRA, 1986, p. 220)

"Irene no céu" é um poema carregado de leveza, seja pela personalidade afável de Irene, seja pela de São Pedro, caracterizado como "bonachão". O tom de leveza está presente no poema analisado de Angélica Freitas, ainda que com tonalidades nostálgicas e melancólicas. Ramôa (2019) identifica que a despretensiosidade é uma característica da lírica da poeta gaúcha e que, caso não seja observada tal especificidade, corre-se o risco de ser lida como mero entretenimento: "[...] a leveza e a acessibilidade características dos poemas freitianos podem parecer como mera tentativa utilitária de entretenimento, do famigerado apelo mercadológico esvaziado de refinamento literário" (RAMÔA, 2019, p. 11). Tendo em vista os traços estilísticos de Freitas presentes em "Célio no céu..." - sua poética transbordando na temática do HIV/aids, praticamente ausente em seu conjunto de obras -, o que nos chama a atenção é a leveza que permeia os poemas de Freitas e Bandeira diante de um tema ainda cercado de tabus nas sociedades ocidentais: a morte.

Como aponta Philippe Ariès (2012), a relação do ser humano com a morte, e o significado dado a ela, se transformaram com o desenvolvimento das civilizações. A partir de textos literários e documentos históricos e religiosos, o autor observou que, na Idade Média, a morte era associada a motivações desconhecidas ou sobrenaturais. Tal percepção modificou-se com o desenvolvimento técnico e científico, possibilitando a descoberta da origem de doenças, a criação de medicamentos e espaços específicos de cuidado para pessoas doentes. Se em outros períodos históricos a morte era encarada com familiaridade e sem medos, é a partir da modernidade que ela ganha outros contornos. A morte passa a ser vista como suspensão da ordem natural, coberta por um véu de silêncio: "Tecnicamente, admitimos que podemos morrer, fazemos seguros de vida para preservar os nossos da miséria. Mas, realmente, no fundo de nós mesmos, sentimo-nos não mortais" (ARIÈS, 2012, p. 100).

O tom dialógico - em Bandeira (1986), marcado graficamente por meio dos travessões, e, em Freitas (2018), pela "conversa" imaginada do eu lírico com Célio - 
também chama a atenção nas duas obras, que abrem mão do hermetismo por meio da coloquialidade. A utilização do pronome "você" coloca o sujeito lírico em uma espécie de diálogo com o "Célio" explicitado no título, como fica evidente na utilização de verbos em primeira pessoa - "me lembro", "me pergunto" -, e de pronomes possessivos, como "tua" cara, "teus" olhos, "tua" casa. Acessando o mundo das próprias lembranças, o eu lírico se direciona a Célio, mesmo sabendo de sua ausência na Terra.

O poema se estabelece como um diálogo entre amigos antigos, coloquial e nostálgico. Inicia relembrando os encontros do amigo com um policial militar, ocorridos há trinta anos. Cronologicamente, o período remete à década de 1990, cujos anos iniciais apresentaram altos índices de infecção pelo HIV e mortes relacionadas à aids - no país, a mortalidade pela doença passa a decrescer somente a partir de 1996 com a distribuição da terapia antirretroviral pelo Sistema Único de Saúde (REIS; SANTOS; CRUZ, 2007). Para o eu lírico, tais lembranças causam boas recordações, a partir de momentos engraçados.

O humor é uma característica presente nos trabalhos poéticos de Angélica Freitas. Segundo Pietrani (2013, p. 31), os poemas de Freitas são carregados de humor e ironia, colocando em questionamento a obrigatoriedade da seriedade e do hermetismo no discurso poético. É pelo humor, conforme apontam Miguel (2017) e Frighetto (2015), que a poeta gaúcha constrói sua identidade poética e tece suas críticas às problemáticas do machismo, à objetificação da mulher e às restrições impostas pelo patriarcado ao corpo e à sexualidade femininas.

Ainda que essas características acompanhem o projeto poético de Freitas, o poema aqui analisado toma rumo diferente, deixando soar uma nota mais melancólica do que humorada. Segundo Bessa (2002), a questão do HIV/aids esteve presente de distintas formas na literatura brasileira. Para o escritor gaúcho Caio Fernando Abreu, autor de diversos contos e novelas que abarcam a temática, "a AIDS era mais do que uma síndrome que afeta o sistema imunológico, ou seja, também era uma epidemia de pânico, preconceito, intolerância, afastamento e isolamento" (BESSA, 2002, p. 117). A exemplo do conto "Linda, uma história horrível", a solidão e a tristeza moldam o livro Os dragões não conhecem o paraíso. O denso clima de aflições e impossibilidades afetivas, gerado pela epidemia de HIV/aids, está presente nos contos que compõem a obra de Abreu (BESSA, 2002, p. 119-120). 
São muitas as diferenças entre as obras de Abreu e o poema de Freitas: o gênero literário, o projeto estético, a realidade histórica em que os textos foram escritos, entre outras. No conto "Linda, uma história horrível", a questão norteadora é a solidão e a angústia diante da finitude da vida, materializada ficcionalmente na corporeidade adoecida do personagem-narrador e no espaço narrativo: a experiência da iminência da morte (MENDES, 1998). Já no poema de Freitas, a morte é concretude nas memórias do sujeito lírico, "realidade" dada e incontornável. Mesmo que não seja o foco principal do presente trabalho, e feitas as devidas distinções, é possível aproximar os trabalhos dos escritores gaúchos pela melancolia que, em Abreu, se faz mais latente e, em Freitas, é dissimulada pela leveza. Uma melancolia própria de temas considerados densos, como a morte - ainda que outros escritores a tematizem de maneiras diferentes.

Retomando o poema "Célio no céu...", é possível traçar algumas considerações sobre o elemento "abajur", indicado no verso 6 . O abajur indica um espaço ou momento de intimidade, objeto comumente posicionado ao lado da cama. A ambientação intimista é também acentuada pela farda despida. Utilizada por policiais e outros profissionais da segurança, pública ou privada, a farda é símbolo de autoridade, de poder e até mesmo de truculência.

A farda do policial queimada "em círculos" pode indicar algo que se repete, que não possui início ou fim, ou também perfeição, unidade, dependendo da interpretação que se fizer do símbolo "círculo". No entanto, o furo na vestimenta representa também um rompimento da ordem, a força militar desarmada perante o desejo. Assim, podemos encarar tal situação como uma espécie de "resistência" de Célio à pequenez (geográfica e/ou moral) do município ao qual residia, indicada nos versos 22, 23, 28, 29 e 30. Ao se formar uma fresta na farda, cria-se uma brecha na hegemonia, apresentada na figura do policial militar. O verbo no pretérito "queimou" também reforça o sentido de intimidade, junto ao abajur e a farda despida, pois seu uso se dá no âmbito metafórico: a queimadura arde, pulsa, tal qual o desejo na fricção dos corpos. A queimadura também cicatriza e deixa marcas.

O poema basicamente se utiliza de verbos no passado. Os verbos em pretérito deixam se ser utilizados nos versos 8, 9 e 10 ("por que me lembro disso / quase trinta anos depois? / porque é engraçado"), onde o sujeito lírico se coloca no presente. Portanto, há um movimento entre passado e presente, próprio da recordação construída pelos referidos versos. 
Isto posto, recorremos às considerações de Bergson (1999) sobre as questões de memória, passado e presente. Para o filósofo francês, a memória "[...] tem por função primeira evocar todas as percepções passadas análogas a uma percepção presente, recordar-nos o que precedeu e o que seguiu, sugerindo-nos assim a decisão mais útil” (BERGSON, 1999, p. 266-267). O autor considera, ainda, que o passado parte de um "estado virtual" em um movimento progressivo até uma situação atual. De acordo com as palavras do autor:

\begin{abstract}
A verdade é que a memória não consiste, em absoluto, numa regressão do presente ao passado, mas, pelo contrário, num progresso do passado ao presente. É no passado que nos colocamos de saída. Partimos de um "estado virtual", que conduzimos pouco a pouco, através de uma série de planos de consciência diferentes, até o termo em que ele se materializa numa percepção atual, isto é, até o ponto em que ele se torna um estado presente e atuante, ou seja, enfim, até esse plano extremo de nossa consciência em que se desenha nosso corpo (BERGSON, 1999, p. 280).
\end{abstract}

As lembranças de trinta anos atrás colocam o eu lírico em um movimento entre passado e presente. Ou seja, o passado, de certa forma, também está integrado ao presente. A partir das reflexões trazidas por Bergson (1999), observamos que o ponto de partida do poema se dá pelo passado ("você levou"), e é por meio dele que emergem as memórias do eu lírico. Em outras palavras, partindo de um "estado virtual", a memória se concretiza no "estado presente e atuante" do sujeito lírico.

As passadas no banheiro da praça também são motivo de lembrança. A prática de encontros sexuais em espaços públicos é bastante cercada de tabus. Como aponta Costa Neto (2005, p. 99), há uma imposição cultural que regula as ações humanas, orientando a manifestação de comportamentos a partir de adequações de tempo e espaço. Tal dinâmica estabelece hierarquias: considerados indevidos para determinadas práticas, os espaços públicos podem instaurar uma "ambivalência ritualística". Existe uma troca simbólica nas interações sexuais em banheiros públicos, nos grafites pornográficos nas portas das cabines, no conjunto de códigos e gestos que incitam o desejo sexual. Assim, as interações sexuais em banheiros coletivos compõem um desvio das normas estabelecidas pela cultura, uma transgressão entre os espaços público e privado. Um espaço de experimentação e de desejo. 
Recuperando os encontros de Célio com o policial militar, localizamos outro processo de resistência dele em relação aos moralismos da cidade possivelmente pequena. Encontros sexuais, estes, acompanhados com fascínio pelo sujeito lírico que, de certa forma, também compactuava com tais ações.

Assim como a farda furada, o banheiro também é uma ruptura com as normas morais. Ao entrar e sair do banheiro público, o personagem Célio transita entre o espaço da ordem do município, e o espaço da "desordem" no banheiro público, onde Célio exercita de forma oculta a sua sexualidade. Podemos abarcar essa reflexão também com o episódio do encontro com o policial, esta figura que representa ordem e autoridade, mas que se entrega à "desordem" da prática sexual dissidente.

O sujeito lírico relembra a cidade onde compartilhou com Célio tais aventuras. "Toda essa atividade" parecia fascinante para o sujeito lírico, pois a transgressão de Célio, da qual também participava o eu lírico (o poema não deixa explícito se essa participação era ativa ou passiva, mas consideramos que o eu lírico se relacionava com a questão através da observação), era uma forma de romper com a normalidade imposta pelas dinâmicas do município, limitações tanto espaciais (cidade pequena), quanto sociais (possível conservadorismo da população): a cidade com poucas possibilidades é apresentada como "fim do mundo".

Os versos 22, 23, 24 e 25 possuem rimas consoantes e toantes, como podemos observar em "era uma cidade / com tão poucas possibilidades / que toda essa atividade / me parecia fascinante." Diante da rima que proporciona um ritmo continuado, a leitura se dá como uma espécie de movimento circular, onde a rima consonantal "idade" será sempre encontrada no final dos versos. Em todo o poema, há pouca presença de rimas, e a utilização da rima neste trecho em específico nos parece proposital. Para remeter às escassas possibilidades do município, a poeta utiliza-se de um único tipo de rima. A repetição de uma única rima possível para representar o cotidiano, a atmosfera pacata e, por vezes, tediosa de uma cidade pequena. Assim, ao ler os versos citados, sempre encontraremos a rima "idade", da mesma forma que Célio e o sujeito lírico sempre se deparavam com o retorno inexorável da mesmice da cidade.

Importante observar que as aventuras transgressoras - como levar um policial para casa ou frequentar banheiros públicos - não compartilham da provável pequenez dos limites (geográficos e/ou morais) do município. Os versos 10 e 11 ("porque é engraçado. / a gente ria o tempo todo.") evidenciam a leveza com que o 
sujeito lírico conduz sua nostalgia. As transgressões sexuais de Célio são encaradas pelo eu lírico com enlevo, e não com olhos discriminatórios, atitude infelizmente comum diante de sexualidades que divirjam, de alguma maneira, da heteronormatividade. Como pontua Sontag (2007, p. 124-125), os setores religiosos conservadores encararam a epidemia de HIV/aids como uma espécie de resposta divina, um castigo imposto por Deus contra a comunidade homossexual, uma condenação moral provocada pelo discurso fanático. Além da despretensiosidade do sujeito lírico perante à sexualidade dissidente, a inserção de Célio no céu o aparta do moralismo religioso, alocando-o em um espaço sagrado que lhe dá origem e destino final.

Em relação ao poema de Bandeira (1986), Freitas utiliza, intertextualmente, parte do título “... no céu”. Ainda que haja leveza na tratativa sobre a morte em ambos os textos, tal característica, como visto, é uma especificidade da poética freitiana, não podendo ser considerada, portanto, uma dinâmica intertextual. Em relação à música dos Beatles, a poeta transforma o "céu de diamantes" de sua fonte originária em título do seu poema "Célio no céu, com toda a sorte de pedras preciosas". Aqui, há a presença demarcada do "céu", e uma reelaboração dos diamantes, apresentados de maneira generalista como "pedras preciosas".

Como explica Samoyault (2008), a literatura é produzida a partir de uma relação com o mundo e consigo mesma. É neste sentido em que se dá a intertextualidade, a existência de outro(s) texto(s) em um texto. As práticas de intertextualidade se dão por meio de citação, alusão, referência, pastiche, paródia, plágio, entre outras. A motivação da recuperação de um texto em outro texto "[...] pode ser aleatória ou consentida, vaga lembrança, homenagem explícita ou ainda submissão a uma modelo, subversão do cânon ou inspiração voluntária" (SAMOYAULT, 2008, p. 9-10).

Para Gérard Genette (2010), o texto não é o objeto da poética, mas a "transtextualidade", a relação subentendida ou não de um texto com outro(s) texto(s), ou, em suas, palavras, "[...] uma relação de co-presença entre dois ou vários textos, isto é, essencialmente, e o mais frequentemente, como presença efetiva de um texto em um outro" (GENETTE, 2010, p. 14). O autor ainda pontua que a transtextualidade se manifesta de formas mais ou menos explícitas, sendo a alusão sua abordagem mais implícita, caracterizando-se como um enunciado que, 
para ser compreendido plenamente, necessita ser observado em relação com outro enunciado.

Nesse sentido, é possível observar as referências subentendidas trazidas pela poeta por meio de alguns elementos alusivos, não apenas em relação ao poema de Bandeira, mas também ao campo musical. A expressão "com toda a sorte de pedras preciosas" remete à música Lucy In The Sky With Diamonds, composta por John Lennon e Paul McCartney e gravada pelos Beatles em 1967. O poema de Freitas faz referência a dois trechos da música - "a girl with kaleidoscope eyes" (em português, "uma garota com olhos de caleidoscópio") e "look for the girl with the sun in her eyes" (em, português, "procure pela garota com o sol em seus olhos") (LUCY, 2017) - quando, no final do texto, o sujeito lírico relembra o brilho dos olhos de Célio.

Na canção Lucy In The Sky With Diamonds, personagens transitam em um mundo fantástico com árvores de tangerina e céus de marmelada. Ao contrário dos rumores de que a música referenciava ao alucinógeno LSD, os compositores se inspiraram no universo da literatura infantil para construir o universo imaginário, em obras de escritores como Lewis Carroll, autor de Alice no País das Maravilhas (ANJOS, 2007). Tanto na música dos Beatles, quanto na obra de Carroll, as personagens participam de aventuras em um universo novo a ser desbravado.

A intertextualidade com a música, como visto, se dá primordialmente pelo título do poema de Freitas. Mas não só. A atmosfera lúdica da aventura e o deslumbramento com o fantástico, essências de Lucy In The Sky With Diamonds e Alice no País das Maravilhas, também são recuperadas nas entrelinhas deste trabalho de Angélica Freitas, mas de maneira irônica. Célio e o sujeito lírico também possuem suas aventuras - aspecto reforçado pelas palavras "história", "atividade fascinante", "aventuras". Todavia, ao contrário do mundo surrealista de Lucy In The Sky With Diamonds, tais aventuras acontecem na "cidade com tão poucas possibilidades": aqui, não há tocas que transportam para universos paralelos, nem paisagens psicodélicas, apenas o banheiro público de uma cidade pequena. As práticas sexuais rompem as limitações do município, tornam-se transgressoras por encontrar os limites da moral, e por isso tornam-se aventuras, pois o inesperado sempre há de nos inserir em um universo fantástico.

Após a partida do eu lírico, Célio permanece na cidade. A partir daí, há um rompimento do contato entre ambos. No retorno à cidade natal, o sujeito lírico se 
depara com a antiga residência de Célio, "um apartamento térreo, / de esquina, / perto do centro". É a partir do contato com a materialidade da existência de Célio (o apartamento) que o eu lírico questiona se o amigo "naquela época já sabia": o quê, não é explícito. Talvez, uma notícia - quem sabe um segredo? - compartilhada por outrem: "até que me contaram".

Tendo em vista o recorte temporal trazido pelo sujeito lírico ("quase trinta anos depois", que rememora o período inicial da epidemia), e o contexto em que está inserido o poema (uma antologia poética voltada à questão do HIV/aids), consideramos que a notícia compartilhada com o eu lírico, mas não compartilhada com o leitor, esteja relacionada à infecção pelo HIV em Célio, e seu adoecimento e falecimento em decorrência da aids. Aqui, percebemos que a questão não está explícita no texto, sendo necessário um olhar mais amplo sobre ela no intuito de acessar a sua profundidade. Como aponta Bessa (1997; 2002), a ausência de enunciação das siglas "HIV" e "aids", ou de outros elementos mais explícitos, é um trajeto percorrido por diversos escritores brasileiros, desde o início da epidemia na década de 1980. Caio Fernando Abreu, Silviano Santiago e Bernardo Carvalho são alguns exemplos. A abordagem subentendida, elíptica, foi utilizada por alguns autores como forma de possibilitar ao leitor outros olhares sobre o HIV/aids na narrativa. Em outras palavras, não mencionar explicitamente o vírus e/ou a doença afastaria do leitor os imaginários sociais construídos acerca da questão, dando a ele margem para uma interpretação mais expandida.

Diferentemente de "Célio no céu...", outros poemas da antologia poética Tente entender o que tento dizer trazem a questão de maneira explícita e nominal, a exemplo dos poemas "Carta para o HIV", de Marcos Visnadi, e "Poema pra Adelaide", de Bruno Cattoni. Assim, décadas após as primeiras produções literárias sobre HIV/aids no Brasil, é possível observar, por meio do poema de Angélica Freitas, que a questão continua sendo abordada de modo implícito.

Apesar de não ter - e não dar - uma resposta, o eu lírico chega à conclusão de que a resposta é o menos importante no conjunto de lembranças. A ausência da resposta é sobreposta por outra lembrança, a do brilho dos olhos de Célio - aqui, uma alusão aos trechos "a girl with kaleidoscope eyes" e "look for the girl with the sun in her eyes" da música dos Beatles - que cintilam tal qual as pedras preciosas que Ihe couberam como destino. Ou seja: maior do que a dúvida é o afeto nutrido 
pelo eu lírico, a vivacidade de Célio que, mesmo morto, brilha em alguma parte do céu.

\section{Considerações finais}

A questão do HIV/aids está presente na literatura brasileira, desde o surgimento de sua epidemia até os dias atuais. Também marca presença na poesia contemporânea por meio da antologia poética Tente entender o que tento dizer, obra que reúne uma pluralidade de vozes e que traz um panorama da poesia brasileira na contemporaneidade.

Debruçando-nos especificamente sobre o poema "Célio no céu, com toda a sorte de pedras preciosas", de Angélica Freitas, percebemos a leveza típica de seus trabalhos resvalando sobre questões ainda cercadas de tabus, como a morte e as práticas sexuais dissidentes. O título do poema faz breve referência ao texto "Irene no céu", de Manuel Bandeira. Ao olharmos para os poemas de Freitas e Bandeira, observamos a atmosfera de leveza na abordagem da morte. A nostalgia é caminho para reencontro do eu lírico com seu amigo, onde trava com ele um diálogo saudoso.

É preciso ressaltar que o HIV/aids é trazido de forma subentendida no poema. Não é citado nominalmente, mas é aludido em alguns versos. Como colocado anteriormente, a literatura brasileira buscou dar diferentes tratamentos estéticos para o tema do HIV/aids. Se autores como Caio Fernando Abreu, Silviano Santiago e Bernardo Carvalho trouxeram a questão de forma implícita, outros como Herbert Daniel e Mário Rudolf davam mais visibilidade à questão, inclusive referenciando-a nominalmente.

Para compreender como se dá a relação da temática com o poema, é preciso um olhar amplo, perceber o seu contexto de publicação e sua posição dentro da antologia poética Tente entender o que tento dizer. Ao ser adicionado à segunda parte da antologia pelo organizador - ou seja, ao espaço dedicado à memória das pessoas que morreram em decorrência da aids -, o poema demarca também uma posição temática, e a elabora esteticamente em toda a sua estrutura.

Há uma ambientação intimista da prática sexual, mas que também se desloca para o ambiente público do banheiro da praça. Entre quatro paredes ou em um espaço público, a sexualidade de Célio é também cerceada pelas limitações morais da cidade em que residia. Enquanto a exerce, também queima a tessitura do 
moralismo, formando um furo, uma resistência contra os invisíveis muros que o cercam. Ao contrário das visões normativas, o sujeito lírico versa com leveza sobre estas questões, estabelecendo uma espécie de diálogo nostálgico e afetuoso com a figura de Célio. Assim, escapa da tradicional visão cristã de pecado, e insere Célio no céu, o lugar dos justos, e o coloca no patamar da valiosidade ao relacionar o seu corpo (os olhos) com o brilho de uma pedra preciosa.

É possível localizar algumas alusões à música Lucy In The Sky With Diamonds, do grupo britânico Beatles, por meio da criação de sentidos em torno de um universo fantástico desbravado por aventuras. No entanto, Angélica Freitas esboça ironicamente em seu poema um universo (anti)fantástico: uma cidade pequena, tediosa e limitada moralmente. Célio escapa dessa normalidade através do sexo, e é por meio dele que se acessa o novo, o extraordinário, o que foge da rotina. Aqui, é pela farda furada e pela porta do banheiro público, e não por uma toca de coelho - como ocorre com Alice na obra de Lewis Carroll -, que o personagem adentra um espaço extraordinário. O sentido de tédio do município também é acentuado no texto pela repetição de determinadas rimas.

$\mathrm{Na}$ tentativa de trazer algumas considerações finais, mas não extinguir as possibilidades de análise e interpretação da obra, percebemos que "Célio no céu, com toda a sorte de pedras preciosas" possibilita reflexões sobre sexualidade de maneira mais aberta, trazendo o $\mathrm{HIV} /$ aids para o campo da ausência e da melancolia, mas também da leveza. Ao relacionar a questão com as práticas sexuais dissidentes, foge da argumentação fácil e moralista da "promiscuidade", que permeou as discussões sobre HIV/aids, principalmente nas primeiras décadas de seu surgimento. Assim, o poema humaniza a questão do HIV/aids, encara com leveza a morte e as transgressões sexuais e aproxima o leitor de um tema que necessita de constantes reflexões, discussões e ações, principalmente em um mundo cada vez mais fechado para as diferenças.

\section{Referências Bibliográficas}

ALTMAN, Dennis. Poder e comunidade: respostas organizacionais e culturais à AIDS. Rio de Janeiro: Relume-Dumará: ABIA: IMS/UERJ, 1995.

ALÓS, Anselmo Peres (org.). Poéticas da masculinidade em ruínas: o amor em tempos de aids. Santa Maria: UFSM: PPGL, 2017. 
ANJOS, Francisco Flávio Oliveira dos. The Beatles: ensaio sobre a ética do amor. Dissertação (Mestrado em Ciências Sociais). Universidade Federal do Rio Grande do Norte, Rio Grande do Norte, RN, 2007. Disponível em: https://repositorio.ufrn.br/jspui/bitstream/123456789/13521/1/TheBeatlesEnsaio_Anjo s_2007.pdf. Acesso em: 04 mar. 2021.

ARIÈS, Philippe. História da morte no Ocidente: da Idade Média aos nossos dias. Rio de Janeiro: Nova Fronteira, 2012.

BANDEIRA, Manuel. Irene no Céu. In: BANDEIRA, Manuel. Libertinagem: poesia completa e prosa. Rio de Janeiro: Editora Nova Aguilar, 1986.

BATISTA, Adriane Figueira. A contaminação discursiva na obra Pequenas epifanias, de Caio Fernando Abreu. Revista Crioula, São Paulo, n. 17, jun. 2016. Disponível em: http://www.revistas.usp.br/crioula/article/view/111930. Acesso em: 30 jul. 2020.

BERGSON, Henri. Matéria e memória: ensaio sobre a relação do corpo com o espírito. 2. ed. São Paulo: Martins Fontes, 1999.

BESSA, Marcelo Secron. Histórias positivas: a literatura (des)construindo a aids. Rio de Janeiro: Record, 1997.

BESSA, Marcelo Secron. Os perigosos: autobiografias \& aids. Rio de Janeiro: Aeroplano, 2002.

COSTA NETO, Francisco Sales da. Banheiros Públicos: Os bastidores das práticas sexuais. Dissertação (Mestrado em Ciências Sociais). Universidade Federal do Rio Grande do Norte, Rio Grande do Norte, 2005. Disponível em: https://repositorio.ufrn.br/bitstream/123456789/13573/1/BanheirosP\%c3\%bablicosBa stidores_CostaNeto_2009.pdf. Acesso em: 08 mar. 2021.

FREITAS, Angélica. Célio no céu, com toda a sorte de pedras preciosas. In: MELLO, Ramon Nunes (org.). Tente entender o que tento dizer: poesia + hiv/aids. Rio de Janeiro: Bazar do Tempo, p. 100-101, 2018.

FRIGHETTO, Gisele Novaes. Um útero é do tamanho de um punho, ou sobre as interdições do feminino. In: Estudos Linguísticos, São Paulo, n. 4, v. 44, set./dez. 2015, p. 1303-1317. Disponível em: https://revistas.gel.org.br/estudoslinguisticos/article/view/1058. Acesso em: 28 jul. 2020.

FONSECA, Leandro Noronha da. HIV/aids e narrativas pós-coquetel na poesia contemporânea brasileira. Monografia (Especialização em Mídia, Informação e Cultura). Centro de Estudos Latino-americanos sobre Cultura e Comunicação, Escola de Comunicações e Artes, Universidade de São Paulo, São Paulo, 2019. Disponível em: http://celacc.eca.usp.br/?q=pt-br/blogs/hivaids-narrativas-poscoquetel-poesia-contemporanea-brasileira. Acesso em: 30 jul. 2020.

GENETTE, Gerárd. Palimpsestos: a literatura de segunda mão. Belo Horizonte: Edições Viva Voz, 2010. 
GUÉRIOS, Rosário Farani Mansur. Dicionário etimológico de nomes e sobrenomes. 3. ed. São Paulo: Ave Maria, 1981.

LUCY In The Sky With Diamonds. Compositores: Paul McCartney e John Lennon. Universal Music, 2017. Faixa musical (3m58s). Disponível em: https://www.youtube.com/watch?v=2RoA0QTZ-bM\&ab_channel=TheBeatlesVEVO. Acesso em: 08 mar. 2021.

MELLO, Ramon Nunes. (org). Tente entender o que tento dizer: poesia + hiv/aids. Rio de Janeiro: Bazar do Tempo, 2018.

MENDES, Fernando Oliveira. Linda, uma história horrível: a literatura encontra o vírus da AIDS. Itinerários. Araraquara, n. 13, 1998. p. 217-223. Disponível em: https://periodicos.fclar.unesp.br/itinerarios/article/view/2858/2624. Acesso em: 08 mar. 2021.

MIGUEL, Renata. Resistência através do riso em Angélicas Freitas. In: Mosaico. São José do Rio Preto, 2017. p. 211-231. Disponível em: http://www.olhodagua.ibilce.unesp.br/index.php/revistamosaico/article/viewFile/423/3 93. Acesso em: 28 jul. 2020.

OLIVEIRA, Antonio Eduardo de. Corpo e memória na obra de Caio Fernando Abreu. In: COSTA, Horácio et al (org.). Retratos do Brasil homossexual: fronteiras, subjetividades e desejos. São Paulo: Editora da Universidade de São Paulo: Imprensa Oficial, p. 169-180, 2010..

PIETRANI, Anélia Montechiari. Questões de gênero e política da imaginação na poesia de Angélica Freitas. In: Revista Fórum Identidades, Itabaiana, ano VII, n. 14, v. 14, jul./dez. $2013 . \quad$ p. 25-38 Disponível em: https://seer.ufs.br/index.php/forumidentidades/article/view/2051. Acesso em: 28 jul. 2020.

RAMÔA, Julia Palma. Um útero é do tamanho de um punho: o feminino e o feminismo no material poético de Angélica Freitas. Dissertação (Mestrado em Letras Vernáculas). Universidade Federal do Rio de Janeiro, Rio de Janeiro, RJ, 2019. Disponível em: http://www.posvernaculas.letras.ufrj.br/images/Posvernaculas/3mestrado/dissertacoes/2019/Disserta\%C3\%A7\%C3\%A30\%20Julia\%20Ramoa_com pleta.pdf. Acesso em: 07 mar. 2021.

REIS, Ana Cristina; SANTOS, Elizabeth Moreira dos; CRUZ, Marly Marques da. A mortalidade por aids no Brasil: um estudo exploratório de sua evolução temporal. Epidemiol. Serv. Saúde, Brasília, v. 16, n. 3, p. 195-205, set. 2007 . Disponível em: $\quad$ http://scielo.iec.gov.br/scielo.php?script=sci_arttext\&pid=S167949742007000300006. Acesso em: 29 jul. 2020.

SAMOYAULT, Tiphaine. A intertextualidade. São Paulo: Aderaldo \& Rothschild, 2008.

SONTAG, Susan. Doença como metáfora, aids e suas metáforas. São Paulo: Companhia das Letras, 2007. 